\title{
O papel dos Estados Unidos na Reforma do Setor de Segurança do Haiti (1994-2004) ${ }^{1}$
}

\author{
The role of United States in the \\ Security Sector Reform of Haiti \\ (1994-2004)
}

El papel de Estados Unidos en la Reforma del Sector de Seguridad de Haití (1994-2004)

DOI: $10.21530 /$ ci.v16n2.2021.1138

\section{Copyright:}

- This is an open-access article distributed under the terms of a Creative Commons Attribution License, which permits unrestricted use,

distribution, and reproduction in any medium, provided that the original author and source are credited.

- Este é um artigo publicado em acesso aberto e distribuído sob os termos da Licença de Atribuição Creative Commons, que permite uso irrestrito, distribuição e reprodução em qualquer meio, desde que $o$ autor $e$ a fonte originais sejam creditados.
João Fernando Finazzi ${ }^{2}$

Reginaldo Mattar Nasser ${ }^{3}$

\section{Resumo}

A Reforma do Setor de Segurança (RSS) do Haiti no que se refere às ações da polícia e das forças armadas tornou-se objeto fundamental das missões da ONU. A literatura sobre o tema tem enfatizado o papel de diferentes agências internacionais nesse processo, mas sem dar o devido destaque à presença dos EUA. Nosso objetivo é demonstrar que havia, no processo de RSS do Haiti e de constituição da atual Polícia Nacional Haitiana, elementos

1 Este trabalho foi feito com o apoio de uma bolsa CAPES através do Instituto Nacional de Ciência e Tecnologia para Estudos sobre os Estados Unidos (INCT-INEU). Processos 88887.141289/2017-00 e 88887.333701/2019-00.

2 Doutorando em Relações Internacionais pelo Programa de Pós-Graduação em Relações Internacionais San Tiago Dantas (Unesp, Unicamp, PUC-SP). Atualmente é professor temporário no curso de Relações Internacionais da PUC-MG (Poços de Caldas).

(jffinazzi@yahoo.com.br). ORCID: https://orcid.org/0000-0001-8986-8858.

3 Livre-Docente em Relações Internacionais (PUC-SP). Professor Associado da PUC-SP e do Programa de Pós-Graduação em Relações Internacionais San Tiago Dantas (Unesp, Unicamp, PUC-SP), São Paulo, Brasil.

(reginaldonasser@gmail.com). ORCID: https://orcid.org/0000-0001-5674-4197. Artigo submetido em 03/11/2020 e aprovado em 01/03/2021. 
que podem auxiliar no entendimento da relação entre as organizações internacionais e a política de poder dos EUA entre 1994 e 2004.

Palavras-chave: EUA, Haiti, ONU, reforma do setor de segurança, operações de paz.

\begin{abstract}
Haiti's Security Sector Reform (SSR) relating to the police and armed forces became the main subject of UN missions. Haiti's SSR literature has emphasized the role of different international agencies, but still little emphasis is placed on the role of the USA. This work explores the role of the USA in the Haitian SSR between 1994 and 2004. We seek to demonstrate that the SSR of Haiti and the constitution of the contemporary Haitian National Police has elements that can help in understanding the relationship between international organizations and the US power politics during the analyzed period.
\end{abstract}

Keywords: EUA, Haiti, United Nations, security sector reform, peacebuilding.

\title{
Resumen
}

La Reforma del Sector de la Seguridad (RSS) de Haití relacionado con la policía y las fuerzas armadas se convirtieron en el objeto más importante de las misiones de la ONU. La literatura sobre RSS de Haití ha enfatizado el papel de diferentes agencias internacionales, todavía se hace poco énfasis en el papel de los EE. UU. Este trabajo explora el papel de Estados Unidos en la RSS de Haití entre 1994 y 2004. Buscamos demostrar que la RSS de Haití y la constitución de la actual Policía Nacional de Haití tiene elementos que pueden ayudar a comprender la relación entre las organizaciones internacionales y la política de poder de EE. UU. durante el período analizado.

Palabras clave: EEUU, Haití, ONU, reforma del sector de la seguridad, operaciones de paz.

\section{Introdução}

Em 1994, a intervenção da ONU no Haiti é a única da história que tinha como objetivo declarado realizar mudança de regime, restaurar a democracia e reconduzir o presidente deposto, Jean-Bertrand Aristide. Para tanto, seria preciso realizar a Reforma do Setor de Segurança (RSS), a profissionalização das Forças Armadas do Haiti (FADH) e a criação de uma polícia nacional, ambas sob controle civil democrático. Contudo, o processo de democratização logo começou a se 
deteriorar e, a partir do final dos anos 90, se encontrava em profundo declínio - levando a uma nova ruptura em 2004.

O insucesso das ações da ONU em alcançar seus objetivos levou à elaboração de uma série de análises com o intuito de aperfeiçoar os esforços da intervenção, realçando a incapacidade de setores da sociedade, em geral, e das elites haitianas, em particular, de realizarem aquilo que seria um acordo nacional sobre o papel a ser atribuído aos atores armados do país, sugerindo uma atuação mais incisiva da "comunidade internacional". No contexto de uma nova intervenção militar, em 20044, o secretário-geral da ONU, Kofi Annan, declarou que o Haiti não tinha capacidade para resolver seus próprios problemas de forma autônoma e que deveria ser ajudado por atores internacionais (Annan 2004).

Essa acepção, certamente benigna da intervenção internacional, segundo a qual a crise haitiana possuía causas exclusivamente endêmicas, passou a ser desafiada nos últimos anos, quando novas análises passaram a atribuir maior relevância aos fatores externos para a sua recorrência. Reconheceu-se não apenas a existência de falhas nas estratégias de atuação de diversas agências e organizações internacionais na RSS do Haiti, ao longo dos anos 1990, mas também em como essa múltipla atuação foi fator de deterioração do processo de democratização dos anos 1990 (Mobekk 2016; Burt 2016).

Se podemos constatar, por um lado, a existência de uma literatura preocupada com o papel dos atores não estatais nas operações de paz no Haiti, por outro, há que reconhecer também que os interesses e os papéis exercidos pelos EUA, em relação à RSS, são raramente enfatizados, ainda que o considerem como um ator relevante (Mobekk 2016: 6). Essa afirmação se choca não apenas com a contínua influência que os EUA exercem sobre o Haiti, desde a ocupação de 1915-345, mas também com a importância fundamental que tiveram tanto na criação das missões da ONU e da OEA que resultaram na intervenção, em 1994, quanto para a execução dos mandatos durante os anos 1990. Já em 2008, na

4 Em abril de 2004, após intervenção inicial de uma coalizão liderada pelos EUA, a ONU cria a Minustah, que fica em vigência por 13 anos no país, inaugurando uma nova etapa das operações de paz no Haiti, com um importante engajamento do Brasil na condição de comandante militar da missão e de maior contribuidor de tropas. A RSS foi um dos objetivos declarados fundamentais da operação.

5 A contínua influência dos EUA no Haiti é tão significativa que alguns historiadores a consideram um elemento fundamental para o estudo da própria história do país, mesmo quando se avalia o período posterior à 1934 . Além da proximidade geográfica e dos legados de ocupações, questões como a transformação das Forças Armadas, os movimentos nacionalistas do século XX, a dependência financeira, a manutenção da ditadura dos Duvalier (57-86), o processo de industrialização do Haiti, e a diáspora haitiana, possuem laços estreitos com a atuação dos EUA. Ver, p. ex.: Pamphile (2015); Robinson (1996); Trouillot (1990). 
vigência do mandato da Minustah, o próprio diretor da Polícia Nacional do Haiti (PNH) reconheceu, junto à embaixadora norte-americana no Haiti, que, sem a assistência do governo dos EUA, a academia de polícia, criada em 1995, não existiria (Wikileaks 2008).

Além disso, há fortes indícios de que a experiência militar dos EUA no Haiti se tornou para seus estrategistas um importante aprendizado para atuar em contextos de reconstrução pós-conflitos armados sob a égide da ONU. Durante a operação de 1994, o então embaixador dos EUA no Haiti, William L. Swing, declarou que a experiência adquirida no país seria vista pelo governo dos EUA como algo que pudesse ser adotado em quaisquer outras situações do mundo consideradas como similares (Goto 2016). Há relatos de que a atuação do general David Petraeus, que supervisionou parte desse processo, na condição de tenentecoronel, serviu como um verdadeiro laboratório de testes para suas teses, que foram, posteriormente, empregadas no contexto da "guerra ao terror", quando se tornou comandante das forças militares no Iraque (2007-8) e Afeganistão (2010-11) (Gericke 2010).

Raymond Kelly, comissário-geral de polícia da cidade de Nova York e um dos executores da RSS no Haiti, ao participar de workshop promovido pelo Departamento de Estado (DOS) e Departamento de Justiça (DOJ) sobre policiamento em "democracias emergentes”, em Washington, em 1995, realçou em seu discurso que os EUA “deveriam estar preparados para lidar em outras democracias emergentes" com os assuntos de reforma policial, prisional e judiciária, considerando a sua experiência no Haiti (US 1997). O próprio DOS reconheceu que o envio de policiais norte-americanos para as operações da ONU tinha se tornado, já no início dos anos 1990, uma "ferramenta vital para a política exterior dos EUA" (US 2005).

Uma vez que, desde 1993, todas as missões da ONU no Haiti tiveram como objetivo a realização da RSS, mesmo que nunca mencionado explicitamente (Mobekk 2016: 4), julgamos que analisar o papel dos EUA nesses esforços permite compreender, de certo modo, a atuação internacional dos EUA no que se refere a contextos de ações multilaterais com a presença de organizações internacionais. Nos últimos anos, a RSS tornou-se um dos principais instrumentos por meio dos quais uma ampla gama de atores estatais e não estatais têm buscado influenciar os processos de reconstrução de Estados conforme definido pela "Doutrina Capstone” em 2008. A importância da RSS como parte integral das operações de paz foi reforçada em abril de 2014, quando o Conselho de Segurança da 
ONU (CSONU) aprovou, unanimemente, a primeira resolução sobre o tema, destacando o papel exercido pelo engajamento de uma ampla coalizão de atores na sua implementação (ONU 2014).

Atualmente, a noção de que a RSS seria crucial para a reconstrução em contextos de conflitos armados, em que a fragilidade estatal é considerada como uma das principais causas, também foi aceita como um pressuposto inquestionável entre os doadores internacionais para o desenvolvimento e segurança, compondo parte de um procedimento padrão de ação internacional, implementado por grandes potências, agências de desenvolvimento e organizações internacionais em diversas regiões no mundo (Sedra 2018).

Com este artigo, pretendemos contribuir para o entendimento da atuação dos EUA no Haiti entre 1994 e 2004, mapeando elementos da RSS que se articulam com a estratégia política de uma grande potência na defesa de seus interesses. Argumentamos que, mesmo que a RSS possua especificidades contemporâneas, ela se insere num longo padrão estratégico de atuação dos EUA. Para explicar o papel da RSS no Haiti, julgamos fundamental compreender o contexto político e social a partir do qual ela emerge, levando em consideração a dinâmica da ação das forças sociais que condicionam a implementação da RSS com o potencial de transformar as relações entre Estado e Sociedade (Cox, 1983).

Além disso, a importância que atribuímos à ação dos EUA no Haiti não significa que outros Estados e atores não estatais não tenham exercido um papel também relevante ou que essas ações não encontraram resistências de grupos organizados na sociedade haitiana. Mas, uma vez que se pretende realçar as continuidades históricas do papel dos EUA no processo de RSS do Haiti, optamos por priorizar uma exposição a partir do encadeamento de fatos relevantes que ajudam a demonstrar nosso argumento. Assim, consideramos ser possível indicar alguns elementos da dinâmica e da forma com que algumas instituições haitianas (como a PNH) vieram a se constituir e que podem nos auxiliar no entendimento da relação entre RSS, organizações internacionais e a política de poder praticada pelas grandes potências.

\section{A doutrina da RSS}

Em termos gerais, a RSS tem, como princípio, a promoção da paz e da segurança, por meio do estabelecimento de "boas práticas" e da "boa governança”, 
envolvendo ações articuladas entre as forças armadas, polícias e atores do judiciário. Dessa perspectiva, os atores envolvidos tentam legitimar suas ações argumentando que se trata de esforços para reconstruir ou reestruturar as forças de segurança de um país, que foi objeto de intervenção, com o objetivo de garantir a plena vigência dos direitos humanos e das normas da democracia liberal (Sedra 2018; Jackson 2018). Esses princípios normalmente se traduzem em ações como a desmobilização de ex-combatentes; a formação de promotores, advogados e juízes; a transformação de leis e processos penais; e a construção de edifícios como delegacias e prisões. Em suma, a RSS envolve amplas ações para reconfigurar as relações de poder entre governantes e governados numa dada sociedade.

A reconstrução das Sociedades e dos Estados afetados por conflitos armados, condição tida como fundamental para alcançar a paz, é um dos principais pilares do projeto da "paz liberal", que ganhou força após o fim da Guerra Fria, com a hegemonia dos EUA na política internacional. A partir dessa perspectiva, as intervenções internacionais multilaterais tornaram-se os principais instrumentos com que as grandes potências ocidentais passaram a atuar de forma multilateral nos contextos de conflitos armados (Duffield 2001). Desse modo, a RSS tornouse uma espécie de corolário do projeto internacional da "paz liberal", com o objetivo declarado de se alcançar os requisitos tidos como necessários para superar o período de transição pós-conflito e concluir a intervenção (Sedra 2010). De acordo com a "Doutrina Capstone", que norteia as operações de paz da ONU, a RSS é um componente essencial para fortalecer o rule of law e garantir o sucesso da operação da paz na medida em que poderia definir uma "estratégia de saída” que dependeria do funcionamento das instituições de segurança nacional (ONU 2008, 27).

O entendimento dos processos de reconstrução como um empreendimento limitado a um determinado período de tempo, prevendo uma "estratégia de saída”, é um dos principais argumentos utilizados pelos entusiastas do projeto da "paz liberal" para diferenciar as intervenções contemporâneas de experiências internacionais anteriores, como o colonialismo europeu. De acordo com Paris (2010), embora o statebuilding possa conter algumas "reminiscências coloniais", um dos aspectos que o distingue daquelas experiências é que as missões contemporâneas, por mais duradouras e intrusivas que sejam, são feitas a partir de um mandato temporal e transitório e a pedido do governo local, diferentemente das antigas colônias, que eram posses das metrópoles. A RSS é, portanto, o conjunto de 
esforços por meio dos quais seriam criadas as condições para a constituição do "autogoverno" no que tange à participação dos atores e das instituições nacionais de segurança (Jackson 2011). Mas, é preciso levar em consideração que há resistências locais aos preceitos liberais inseridos nos projetos de reforma e que podem implicar em formas de negociação entre as demandas locais e os preceitos universalizantes das agências internacionais, resultando numa "paz liberal híbrida” (Richmond 2012).

A relação entre os intentos de intervenção e de reconstrução internacional e a necessidade de se diferenciar de antigos empreendimentos coloniais tem colocado uma série de tensões e dilemas na formulação da RSS. Esses dilemas são objeto de infindáveis discussões sobre qual seria o limite ideal entre o comando internacional da reforma e o respeito pela soberania dos Estados ou, ainda, sobre a maneira de se lidar com fontes tradicionais de autoridade não estatais. Apesar disso, há um relativo reconhecimento da ausência de evidências de que a RSS tenha, de fato, contribuído para alcançar de modo bem-sucedido os fins declarados (Sedra 2018; Donais 2018; Burt 2016). Parte da literatura sobre RSS tenta responder a essa constatação de ineficiência a partir da perspectiva das teorias de resolução de problemas, aceitando os postulados que limitam e criam as possibilidades de atuação a partir das próprias instituições existentes, mas sem se preocupar com as origens e possibilidades de transformação dos fundamentos das relações sociais e de poder que criam e mantêm essas mesmas instituições (Cox 1981).

No caso da RSS do Haiti, consideramos ser necessário dar o devido destaque ao papel dos EUA durante o período analisado, reconhecendo alguns processos que podem indicar o estabelecimento e a manutenção de vínculos políticos arraigados na relação que os EUA vieram a estabelecer com o setor de segurança haitiano.

\section{A intervenção de 1994 e seus antecedentes}

O final dos anos 1980, no Haiti, é marcado por um período conturbado de violência política, com a fuga de Jean-Claude Duvalier no início de 1986, a elaboração de uma nova Constituição em 1987 e a realização de eleições gerais em 1990 (Weiner, Engelberg e French 1993). O contexto foi também caracterizado por diferentes golpes de estado e pelo assassinato de opositores de Duvalier 
por membros das FADH e ou milícias (Trouillot 1990). É nesse período que as Organisations Populaires ascendem em importância como movimento de oposição à ditadura, compostas por grupos de camponeses empobrecidos, sindicatos, organizações estudantis, movimentos dos comitês eclesiásticos de base e os comitês urbanos de bairros, formados, na maioria dos casos, pelos filhos da primeira geração de ex-camponeses que passaram a habitar os centros urbanos. Essa será, em termos gerais, a base eleitoral do movimento Fanmi Lavalas, que lançará o então padre de uma igreja na favela de Cité Soleil, Jean-Bertrand Aristide, à presidência em 1991 (Smarth 1998; Robinson 1996).

A vitória de Aristide nas eleições representou um importante marco histórico para o Haiti. Primeiro presidente democraticamente eleito, com $67,5 \%$ de votos num pleito que reuniu $85 \%$ de eleitores sob supervisão de monitores internacionais (Jefferies 2001). Seus discursos públicos reivindicavam profunda transformação da sociedade haitiana, com forte apelo ao enfrentamento da miséria, à defesa da democracia, do nacionalismo e da distribuição de terras. Aristide também manifestava, recorrentemente, em seus discursos públicos, o intuito de reformar as FADH, colocando-as sob controle civil e melhorando as condições de trabalho dos soldados de baixa patente (Jefferies 2001). Os primeiros meses do seu governo foram marcados pela prisão de líderes ligados ao regime dos Duvalier que faziam parte das FADH, do sistema judiciário, das polícias e das milícias, além de apoiar a atuação de ONGs nacionais e internacionais e de organizações multilaterais como OEA e ONU (Sprague 2012). Aristide também afastou o alto comando das FADH, dividiu as forças de segurança entre Exército e Polícia e aboliu os chefs de section, autoridade política que centralizava as funções associadas aos papéis de prefeito, juiz e polícia no contexto rural haitiano (Mobekk 2016).

O golpe que removeu Aristide da presidência, em setembro de 1991, teve importante participação e apoio de membros das FADH, de milícias e de outros grupos sociais da "elite duvalierista" (Trouillot 1990; Jefferies 2001; Sprague 2012). Ao longo do movimento, membros da Agência de Defesa Haitiana e do Serviço de Inteligência Nacional (criado com apoio financeiro dos EUA) tiveram um relevante papel, assumindo depois posições de destaque no novo governo liderado por uma junta militar (Weiner, Engelberg e French 1993; Engelberg 1994). Após o golpe, grupos militares, paramilitares e civis armados passaram a efetuar atos sistemáticos de violência, como estupros e massacres, contra os oponentes do regime e os apoiadores de Aristide, ações amplamente denunciadas na imprensa internacional (Sprague 2012; Raspberry 1992). O episódio também 
aprofundou ainda mais o fluxo de refugiados haitianos que deixavam o país, desde o final dos anos 1980, em sua quase totalidade para os EUA.

Logo após a retirada de Aristide, os militares norte-americanos iniciaram o planejamento de diferentes ações para intervir no Haiti, antevendo a possibilidade de conflito com as forças haitianas (Ballard 1998). Embora, diplomaticamente, os EUA tenham atuado, desde o final do governo $\mathrm{H}$. W. Bush, visando a articular uma coalizão multilateral para a intervenção, com autorização de OEA e ONU, da perspectiva operacional, as ações foram quase exclusivamente resultado das ações norte-americanas (Kreps 2007; Ballard 1998).

Nesse contexto, a OEA adotou uma resolução instando todos os Estados a suspenderem todo tipo de relações econômicas com o Haiti, com exceção daquelas voltadas para a ajuda humanitária, destacando o pedido para não proverem quaisquer tipos de assistência militar, policial ou de segurança (OEA 1991). Uma ordem executiva dos EUA, em outubro de 1991, estabeleceu um embargo unilateral, mas com exceção para alguns produtos de empresas norte-americanas. Logo, esse embargo passou a ser contornado por, ao menos, mais 12 países, principalmente a partir do território da República Dominicana (Malone 1997; Bromley 2007). Embora não se saiba exatamente o papel dos EUA no que tange à questão do embargo de armas, Nairn (1996) indica que, em meados de 1993, houve o envio de alguns carregamentos com o intuito de apoiar a formação de um grupo paramilitar opositor de Aristide.

Entre setembro de 1991 (retirada de Aristide) e outubro de 1994 (intervenção da coalizão liderada pelos EUA), as pressões internacionais contra a junta militar cresceram progressivamente. Em fevereiro de 1993, ONU e OEA aprovaram a primeira missão conjunta para o Haiti com o objetivo oficial de monitorar a garantia de direitos humanos e fortalecer as instituições judiciárias, policiais e prisionais. No planejamento para a missão, os EUA já consideravam um envio posterior de monitores policiais internacionais para o treinamento das forças de segurança haitianas, formados por membros das polícias canadenses, francesas e militares norte-americanos (Ballard 1998). Em 16 de junho de 1993, o CSONU tomou unanimemente sua primeira decisão sobre o Haiti baseando-se no Capítulo VII (ONU 1993a), com o objetivo declarado de fazer valer o mandato da missão conjunta OEA/ONU (MICIVIH), para impor ao Haiti um embargo internacional de petróleo e de armas (equipamentos, munições, veículos etc.).

Durante os dois anos em que esteve no exílio, nos EUA, Aristide liderou uma ampla campanha política para influenciar membros no governo e no congresso 
norte-americano para que, de alguma forma, apoiassem sua recondução ao Haiti na condição de presidente, especialmente após a vitória eleitoral de Clinton em 1993. A política de repatriação forçada do governo norte-americano frente ao crescente número de pessoas que deixavam o país, mantida durante a presidência de Clinton, também teve um papel de grande importância no aumento das mobilizações para a resolução da crise haitiana, principalmente pela participação de grupos organizados da diáspora haitiana nos EUA e do Black Caucus no Congresso. A questão também chegou à Suprema Corte, que decidiu favoravelmente pela manutenção da política e gerou amplas condenações de diversos atores internacionais, notavelmente do Alto-Comissariado das Nações Unidas para Refugiados (Malone 1997; Girard 2004).

Com o isolamento do governo e as pressões do embargo, Raoul Cedras, comandante das FADH e líder da junta militar, sinalizou, em julho de 1993, que iria realizar uma transição pacífica para o governo de Aristide ao assinar com ele os Acordos da Ilha do Governador, mediados pelos EUA. No texto do acordo, ambas as partes manifestaram concordância com a presença de funcionários da ONU para a assistência à "modernização" das FADH e a criação de uma nova polícia, com a concessão de anistia e a nomeação de um novo comandante das FADH, por parte de Aristide, após a saída de Cedras do governo em 30 de outubro de 1993. Reforçando os termos do acordo, no dia 16 de julho, parlamentares e membros da sociedade civil haitiana assinaram o Pacto de Nova York, assegurando a tramitação urgente de uma lei para o estabelecimento de uma nova força policial (ONU 1993b). Após a assinatura do acordo, o CSONU suspendeu o embargo internacional, em 27 de agosto, sob a condição do seu cumprimento (ONU 1993c).

Após solicitação de Aristide, em carta enviada ao Secretário-Geral da ONU, em julho de 1993, estipulando os termos para a criação de uma nova força policial e da profissionalização das FADH (ONU 1993d), o CSONU aprovou, em 23 de setembro do mesmo ano, uma segunda missão, a United Nations Mission in Haiti (UNMIH). Reforçando o apoio à transição para o governo de Aristide, o CSONU determinou que os monitores policiais da ONU deveriam "prover orientação e treinamento a todos os níveis da polícia haitiana, bem como monitorar o modo pelo qual as operações seriam implementadas" (ONU 1993e), durante um período inicial de seis meses, renováveis a partir de avaliação de progresso feita pelo Secretário Geral. No dia 11 de outubro de 1993, o desembarque das tropas norte-americanas e canadenses da UNMIH, a bordo de navio dos EUA, 
foi rechaçado no porto da capital haitiana por paramilitares e apoiadores do regime. De acordo com Malone (1997), o governo Clinton teria calculado que seria melhor evitar a reprodução, em larga escala, nas coberturas televisivas de imagens dos soldados dos EUA mortos, tal como ocorreu, na semana anterior, durante a ação na Somália.

Com o incidente militar, o CSONU rapidamente retomou os embargos ao Haiti (ONU 1993f) e estabeleceu um bloqueio naval (ONU 1993g). Mesmo assim, segundo Bromley (2007), a fronteira do Haiti com a Rep. Dominicana teria se mantido relativamente aberta, registrando-se a passagem frequente de veículos com poucos ou nenhum obstáculo, servindo como local potencial de envio de armas. No final de julho de 1994, os EUA conseguiram autorização do governo dominicano para realizar patrulhas na fronteira com o Haiti (Bromley, 2007).

Em maio de 1994, o governo Clinton emitiu a Decisão Diretiva Presidencial 25 para "Reforma de Operações de Paz Multilaterais" destacando que, sob certas circunstâncias, a participação militar dos EUA é necessária "para persuadir outros [Estados] a participarem em operações que sirvam os interesses dos EUA". Com isso, pretendia esclarecer que a participação dos EUA poderia ser uma forma de exercer influência sobre importantes missões da ONU sem assumir a responsabilidade unilateralmente (US 1994).

De acordo com Cox (1983), as instituições internacionais incorporam regras que facilitam a expansão da ideologia dominante e fornecem a justificativa para a implantação de políticas neoliberais. Os princípios da "boa governança" e da democracia liberal são apresentados como atributos morais obrigatórios pela imposição de condicionalidades pelas instituições. As instituições e regras internacionais são geralmente iniciadas pelo Estado dominante, o qual toma os devidos cuidados de assegurar a aquiescência de outros Estados dentro de uma estrutura informal de influência, que reflete os diferentes níveis de poder e que fundamenta os procedimentos formais de decisão.

Apenas a partir dos meses de junho e julho de 1994 que o Comando do Atlântico dos EUA passou a incluir no seu planejamento militar a criação de uma força multinacional coordenada com a ONU e outras organizações internacionais, visando a utilizar a UNMIH como uma força de continuação da intervenção (Ballard 1998). Conforme documentos do Conselho de Segurança Nacional do governo Clinton, a estratégia dos EUA seria utilizar, ao máximo, o envolvimento multinacional, mas com a exclusividade do treinamento da nova força policial feito principalmente pelo Programa Internacional de Assistência ao Treinamento 
em Investigação Criminal do Departamento de Justiça dos EUA (ICITAP) (NSC 1994).

Em 15 de julho, após a embaixadora dos EUA na ONU, Madeleine Albright, declarar que 11 países prometeram apoio à constituição de uma coalizão internacional para a formação de uma força multinacional no Hait após a retirada da junta militar, o Secretário-Geral da ONU, Boutros-Ghali, advertiu que a organização não conseguiria viabilizar a formação e o financiamento dessa força e solicitou aos EUA liderarem essa ação (Ballard 1998; ONU 1994). De acordo com Ballard (1998), os comandantes militares da intervenção perceberam que o seu sucesso

seria avaliado pela longevidade da presidência de Aristide e pela possibilidade de promover as reformas judiciais e policiais como pilares fundamentais. Em 20 de julho de 1994, Albright pediu formalmente ao CSONU que autorizasse a formação de uma força multinacional liderada pelos EUA no Haiti (Ballard 1998). Dez dias depois, o CSONU declarou que o "regime ilegal" (ONU 1994a: item 3) do Haiti falhou em cumprir com as obrigações dos Acordos da Ilha do Governador, e outras resoluções do próprio Conselho, e autorizou a criação de uma "força multinacional sob comando e controle unificado a qual poderia usar todos os meios necessários para facilitar a partida da liderança militar do Haiti" e proporcionar a criação de "um ambiente seguro e estável que permitirá a implementação dos Acordos da Ilha do Governador" (ONU 1994a: item 4). Um mês depois, teve início a operação Uphold Democracy com 20.000 soldados norte-americanos e outros 5.000 de 24 países diferentes.

\section{O papel dos EUA na RSS do HAITI entre 1994 e 2001}

Entre julho de 1993 e março de 2000, todas as missões autorizadas pelo CSONU sobre o Haiti tiveram, dentre os seus objetivos declarados, a realização da RSS. Ao longo desse período, apesar de Canadá, França e outros países terem colaborado com a RSS, ela foi praticamente organizada e dirigida pelos EUA, com importante atuação nas cidades de Porto Príncipe e Cap Haitien (Bailey, Maguire e Pouliot 2002). Nas regiões rurais, as ações foram de desenvolvimento de projetos na área de saúde pública e educação cívica, em conjunto com a Agência dos EUA para o Desenvolvimento Internacional (USAID) (Benomar 2001).

Entre 1994 e 2001, sob direção e execução dos EUA, as FADH foram completamente desmobilizadas e duas forças policiais (uma interina e a atual 
PNH) foram constituídas após uma série de cursos e treinamentos supervisionados pelos monitores internacionais (Benomar 2001). Mesmo que seja difícil encontrar os limites específicos de cada agência do governo dos EUA, por meio dos recursos e das iniciativas do ICITAP, o DOJ foi responsável por várias dessas ações. Podese citar: o treinamento dos monitores policiais internacionais e dos policiais civis da ONU (os quais posteriormente treinaram a força interina de segurança pública após a desmobilização das FADH); o treinamento de refugiados haitianos que estavam na base de Guantánamo para compor as forças de segurança nacionais; a composição dos treinadores e professores da academia da PNH; a escolha e o veto daqueles que iriam compor a força de segurança - barrando, inclusive, sugestões do próprio governo Aristide (Bailey, Maguire e Pouliot 2002; Mendelson-Forman 2006).

À época, o próprio Secretário de Defesa dos EUA, William J. Perry, declarou que o governo norte-americano também estava treinando a guarda presidencial haitiana, que veio a fazer a segurança pessoal de Aristide (Ballard 1998). Contratada pela USAID, a empresa privada de segurança MVM Inc. forneceu agentes para compor a guarda durante um período de três meses (Girard 2004). Em outubro de 1994, sob a direção de Raymond Kelly, os monitores policiais internacionais iniciaram o processo de formação de uma força interina haitiana de segurança pública em que parte dos membros foram identificados e selecionados a partir de voluntários que então compunham as FADH (Ballard 1998; Mendelson-Forman 2006). Já em dezembro de 1994, essa força interina, que vigorou por um ano, contava com 3.000 membros (ONU 1995). No período entre 1993 e 1998, 40\% (US\$ 138 milhões) de toda a ajuda internacional dos EUA destinada à promoção do rule of law na região da América Latina e Caribe foi para o Haiti. Globalmente, o Haiti também foi o principal destino desse tipo de assistência durante esses anos, com 14,2\% do total (US\$ 1999). Parte significativa dos recursos foi para treinamento, equipamentos e construção da academia da PNH, notadamente através do ICITAP (US 2000).

Diferentemente do que previam os Acordos da Ilha do Governador, Aristide desmobilizou as FADH quando emitiu dois decretos no início de 1995: em 6 de janeiro, reduzindo a força para 1.500 membros e incorporando-a à polícia interina, e em 25 de abril, consolidando a sua completa desmobilização (Mendelson-Forman 2006). Durante esse período, os soldados se articularam em diversos grupos organizados para defender a manutenção das FADH. Segundo Mobekk (2001), a visão predominante entre os soldados dessas organizações 
era a de terem sido abandonados pelos oficiais superiores que se exilaram durante o processo, que eram também vistos como coresponsáveis pela decisão do governo Aristide de desmobilização. Por outro lado, o histórico de graves violências por parte de militares partidários dos governos de Raoul Cedras e dos Duvalier teria sido um dos principais elementos que motivaram, naquele momento, várias mobilizações populares e apelos de ONGs e de grupos de representação de classe haitianos favoráveis à dissolução completa do Exército (Mobekk 2001). Embora não se possa excluir o papel de outras agências e organizações internacionais, parte significativa dos esforços de desmobilização esteve sob a supervisão e execução do ICITAP (Girard 2004; Bailey, Maguire e Pouliot 2002).

Com a desmobilização das FADH, somente 1.500 dos seus 7.000 ex-membros vieram a compor a nova PNH (Mobekk 2001). Apesar da oferta de cursos profissionalizantes, em projeto conjunto da USAID e Organização Internacional para as Migrações (OIM) para realizar a desmobilização das FADH, menos de $6 \%$ conseguiram trabalho por meio do programa (Dworken, Moore e Siegel 1997). A maioria recorreu a outras formas de obtenção de recursos, inclusive com alguns criando, mantendo e aprofundando redes de extorsão, de tráfico de drogas e armas, e de segurança privada. Outros se recusaram a reconhecer a abolição das Forças Armadas, mantendo-se organizados de forma clandestina e cultivando vínculos sociais com membros da nova PNH (Mobekk 2001; Sprague 2012; Cockayne 2009).

Isso significou que a desmobilização das FADH não havia alcançando os objetivos declarados pela RSS de reestruturar as forças de segurança de um modo que pudessem ser responsabilizadas perante um controle civil democrático, mas serviu, conforme Eirin Mobekk (2001), como uma forma de auxiliar as forças dos EUA em garantir a sua própria segurança durante a intervenção.

A nova PNH incluiu parte dos ex-membros das FADH e começou a ser treinada em fevereiro de 1995. Os monitores provinham do governo dos EUA, de empresas privadas de segurança (como DynCorp), da Real Polícia Montada Canadense e da polícia francesa (Girard 2004; Bailey, Maguire e Pouliot 2002; Mobekk 2001). As armas e os equipamentos também vieram, em sua maioria, dos EUA, que sempre foram, ininterruptamente, os maiores exportadores para o Haiti desde os anos 1980 (Muggah 2005). Parte do treinamento da polícia haitiana consistiu na realização e no acompanhamento de rondas ostensivas 
e prisões, em conjunto com os policiais civis da ONU e as tropas militares, e na supervisão diária dos trabalhos das delegacias na capital (Bailey, Maguire e Pouliot 2002).

Embora o envio de recursos dos EUA tenha priorizado a desmobilização das FADH e a formação da PNH (Mobekk 2001), o DOJ e a USAID realizaram uma série de medidas relativas à reestruturação da justiça haitiana, promovendo cursos, treinamentos, assistência e monitoria a juízes e promotores (Bailey, Maguire e Pouliot 2002). Em termos gerais, o engajamento no Haiti foi um ponto de inflexão e oportunidade para a aproximação da DynCorp com o DOS, momento em que ela passou a atuar na realização de programas internacionais de RSS (Broder e Rohde 2007). Segundo Ballard (1998), o DOJ não tinha funcionários treinados para realizar as reformas legais no Haiti, e reservistas militares, cujos trabalhos civis eram na área de justiça criminal, formaram equipes de treinamento com o intuito de auxiliar nos esforços de RSS junto com o DOS. Em 1995, por exemplo, o Comando do Atlântico, junto com a USAID e empresas privadas contratadas, instituiuí vários programas com o objetivo de prover formação jurídica, catalogar os magistrados e registrar o que entendiam ser as necessidades locais (Bailey, Maguire e Pouliot 2002).

Oficialmente, a transição do comando de operações, no Haiti, da Força Multinacional liderada pelos EUA para a missão da ONU (UNMIH) ocorreu em março de 1995 e um grande número de tropas norte-americanas deixou o país em 1996. No entanto, os EUA continuaram não somente com um papel importante de liderança militar da UNMIH, como também mantiveram o engajamento nas ações de RSS. A partir de 1998, a responsabilidade principal do treinamento da PNH começou a ser delegada aos novos oficiais haitianos que haviam sido formados ao longo dos anos precedentes (Neild 1998). Entre 1996 e 2000, o ICITAP continuou fornecendo as diretrizes que os monitores policiais da ONU teriam para treinar a $\mathrm{PNH}$, comandando o planejamento do treinamento de unidades de elite com o objetivo declarado de combater o tráfico de drogas e controlar multidões, fornecendo os equipamentos e veículos à PNH, além de participar na construção de suas instalações (Keller 2010). Também em 1998, o governo do Haiti firmou um contrato com a empresa privada de segurança norte-americana Steele Foundation, formada, em sua maioria, por ex-soldados das forças especiais dos EUA e oficiais de inteligência. A empresa ficou a cargo da Unidade de Proteção Presidencial, efetuando inclusive treinamentos (Democracy Now 2004). 


\section{A continuação do engajamento dos EUA na RSS do Haiti e a crise de 2004}

Desde o final dos anos 90, uma série de acontecimentos mostrava a instabilidade permanente do sistema político haitiano. As eleições legislativas de 1997 não foram aceitas pelo governo nem pela oposição, e a OEA qualificou o pleito como “altamente questionável” (OEA 1998). Desde então, as eleições foram continuamente postergadas até 2000. Durante esse período, o parlamento haitiano bloqueou todas as tentativas de nomeação de um primeiro-ministro por parte do presidente René Préval (eleito em 1995). Com o Parlamento dissolvido em 1999, Préval passou a governar por decreto, aumentando a insatisfação da oposição. Durante as eleições de 2000, a crise política se aprofundou quando o Conselho Eleitoral Provisório mudou a fórmula na contagem de votos. Oposição e OEA qualificaram a medida como inconstitucional e violadora da lei eleitoral haitiana (OEA 2000). Os partidos de oposição boicotaram as eleições presidenciais que ocorreram no final do mesmo ano e se recusaram a reconhecer a vitória que levou novamente Aristide ao poder em 2001 (Gonzalez 2000).

O primeiro ano do segundo governo Aristide foi marcado por ataques armados à Academia da PNH e ao Palácio Nacional, pela suspensão da ajuda dos EUA e de outros doadores internacionais ao governo haitiano, pelo cancelamento de empréstimos previamente acordados com o Banco Interamericano de Desenvolvimento e pelo término da International Civilian Support Mission in Haiti da ONU, que repercutiram imediatamente na economia do país (Hallward 2004).

Mesmo assim, o final da missão não significou o fim do engajamento dos EUA na RSS. Até a sublevação armada que retirou novamente Aristide da presidência, em 2004, a USAID manteve atuação em conjunto com uma organização norteamericana que desenvolvia ações de apoio a escolas de magistratura, treinamento de jornalistas, desenvolvimento de redes de associações legais e de monitoramento de direitos humanos, e promoção de reforma da justiça haitiana (USAID 2015).

A crise política se intensificou com o aumento da repressão aos protestos de grupos organizados da oposição, como o Grupo dos 184 e a Convergence Democratique, por parte da $\mathrm{PNH}$ e de outros grupos armados partidários de Aristide (ONU 2004. Com o objetivo declarado de retirar Aristide da presidência, o grupo paramilitar Front pour la Libération et la Reconstruction Nationale iniciou uma campanha de ataques armados às delegacias policiais das pequenas vilas 
e cidades do Nordeste do Haiti (Sprague 2012; Hallward 2004). De acordo com Sprague (2012), seus principais membros serviram, em algum momento, nas forças de segurança haitianas, como FADH e PNH. Entre 2002 e 2004, as forças da PNH que se encontravam nessas localidades passaram a não oferecer resistência, abandonando seus postos ou, em alguns casos, integrando a insurgência junto com outros grupos armados como as "gangues urbanas" e milícias (que também disputavam entre si o controle local), enquanto mobilizações de massa ocorriam em Porto Príncipe (Sprague 2012; ONU 2004).

As "gangues urbanas" haitianas são vistas, em alguns círculos sociais, como grupos armados legítimos e se relacionam com as disputas partidárias do Haiti em vários níveis de governo. Seja a partir de alianças, seja de bases de militantes ou forças de autodefesa, com formas de atuação que variam ao longo do tempo a partir da conjuntura política e econômica (Kolbe 2013; Kovats-Bernat 2006). Trata-se, muitas vezes, de grupos que se constituíram ao redor de redes do narcotráfico internacional, que executam ações de extorsão, sequestro e homicídio, além de servirem também como forças de defesa frente às violências cometidas pela PNH, FADH, paramilitares ou outros grupos armados (Kolbe, 2013).

É preciso destacar que, em fevereiro de 2004, já tendo a oposição dominado grande parte das cidades e se aproximado de Porto Príncipe, Aristide, um pouco antes de ser deposto, pediu, sem sucesso, o apoio da "comunidade internacional" para ajudar a conter a insurgência, com o apoio à PNH (Cosgrove-Mather 2004). No mesmo dia em que Aristide deixou o país, 29 de fevereiro de 2004, o CSONU autorizou o envio de uma força multinacional para estabilizar o Haiti e "facilitar o fornecimento de assistência internacional à polícia haitiana”, declarando também a sua posterior substituição por uma força da ONU em menos de 3 meses (ONU 2004a). Para os militares norte-americanos, era o início da operação Secure Tomorrow.

\section{Conclusão}

Como pudemos observar, a RSS do Haiti, desenvolvida pela coalizão internacional liderada pelos EUA, não evitou a crise política nem a sublevação armada dos anos 2000. Além disso, esteve longe de construir um setor de segurança sob controle civil democrático e que garantisse o respeito aos direitos humanos. Pelo contrário, os militares desmobilizados e parte da PNH formada, treinada e 
equipada pelos EUA tiveram um papel central nos acontecimentos que levaram à retirada de Aristide em fevereiro de 2004 (Sprague 2012). Frente a isso, parte da literatura tem priorizado a discussão em torno da falta de um “acordo" entre as elites nacionais e de um contínuo engajamento internacional na forma de operações de paz com mandatos ainda mais longos e assertivos. Autores como Mobekk (2016); Sprague (2012); Cockayne (2009); Donais (2005) reconhecem e destacam o papel político que os diversos atores armados da sociedade haitiana (“gangues” urbanas, policiais, ex-militares, paramilitares, seguranças privados) desempenharam nos níveis local, regional e nacional ao exercer simultaneamente funções de provimento de assistência social nos bairros pobres; defesa contra a violência de outros grupos armados; bases partidárias e militantes; meios de ascensão socioeconômica para seus membros; e forças de achaque contratáveis para se contrapor a adversários políticos ou econômicos.

Com este artigo, pretendemos contribuir com o debate sobre a RSS analisando as dinâmicas da atuação dos EUA no Haiti, destacando o encadeamento de alguns acontecimentos que indicam a manutenção de um longo padrão estratégico na busca dos Estados por influência política e domínio de territórios. Não podemos supor que ao longo dos anos analisados não houve resistências a esses esforços, seja por parte de grupos organizados da sociedade civil haitiana, seja a partir de articulações transnacionais, com ou sem a participação de governos. Evitando qualquer pretensão de uma leitura teleológica ou simplista de um processo histórico complexo, almejamos demonstrar que a continuidade da implementação da RSS, por meio de operações multinacionais no Haiti, ofereceu a vantagem estratégica para os EUA de compartilhar os custos políticos da missão com atores estatais e não estatais, contribuindo com a criação de uma percepção de coresponsabilidade pelas ações.

Ainda que se reconheça a participação de outros atores, a RSS do Haiti, entre 1994 e 2004, foi um empreendimento sustentado fundamentalmente pelos EUA. A elaboração de planos para uma intervenção militar assim que acontece o golpe de 1991; a atuação diplomática em OEA e ONU; a presença de Aristide nos EUA para que o governo norte-americano favorecesse sua recondução ao cargo; o deslocamento de navios para o Caribe para o cumprimento dos embargos; o envio expressivo do maior número de tropas; o comando militar da operação - indicavam a importância dos EUA no momento da intervenção. Posteriormente, com o desembarque de tropas militares e policiais no Haiti, a liderança quase exclusiva dos EUA continua se manifestando na implementação pelo ICITAP e 
pela USAID dos esforços de RSS, visando a reestruturar completamente o setor de segurança haitiano.

Essa vantagem estratégica já era reconhecida na Decisão Diretiva Presidencial 25 do governo Clinton (US 1994), segundo a qual a participação dos EUA nas missões da ONU ofereceria a possibilidade de influenciar e, ao mesmo tempo, diluir entre os outros Estados e agências as possíveis percepções de uma responsabilização unilateral dos EUA. Ou seja, a presença de contingentes militares de outros Estados mostrava a vantagem de transmitir uma imagem aos haitianos de que a intervenção não era uma ação unilateral dos EUA (US 1997).

Assim, podemos concluir que as considerações estratégicas dos EUA sobre a atuação da UNMIH diziam respeito ao potencial que ela teria para aparecer como representante da chamada "comunidade internacional" a partir do posicionamento da ONU e de pressões em Washington frente à crescente crise de refugiados haitianos. O envolvimento da OEA também poderia reduzir as percepções potencialmente negativas da influência dos EUA no Caribe, as quais teriam se deteriorado após as invasões de Granada (1985) e Panamá (1989).

Para os EUA, mesmo que a RSS não tenha concretizado seus fins declarados, diferentemente do que se supõe ser a realização de um "interesse nacional” stricto sensu, e independente das forças sociais em disputa, é possível identificar que as ações intervencionistas ao longo dos anos 1990 trouxeram ganhos significativos (políticos, econômicos ou de prestígio) para alguns atores norte-americanos com capacidade de influenciar a ação do Estado. A RSS, enquanto estratégia de atuação, além de auxiliar na intervenção e servir como o teste de um projeto de construção de Estado que se justificava no discurso da "paz liberal”, também ajudou a promover várias empresas privadas que passaram a atuar na indústria da segurança globalmente.

\section{Referências}

Annan, Kofi. 2004. "In Haiti for the Long Haul”. The Wall Street Journal, Março 16, 2004. Ballard, John. 1998. Upholding Democracy: The United States Military Campaign in Haiti, 1994-1997. Westport: Praeger Publishers.

Bailey, Michael; Robert Maguire and John Pouliot. 2002. "HAITI: Military-Police Partnership for Public Security”. In Policing the New World Disorder: Peace Operations and Public Security, Honolulu: University Press of the Pacific (Eds. Robert Oakley, Michael Dziedzic and Eliot Goldberg). 
Benomar, Jamal. 2001. "Rule of Law Technical Assistance in Haiti: Lessons Learned”. Submitted at A World Bank Conference: Empowerment, Security and Opportunity Through Law and Justice. Saint Petesburg.

Broder, John e David Rohde. 2007. "State Department use of contractors leaps in 4 years”. The New York Times, October 24.

Bromley, Mark. 2007. "United Nations Arms Embargoes: Their Impact on Arms Flows and Target Behaviour. Case Study: Haiti, 1993-94.” SIPRI: Stockholm International Peace Research Institute.

Burt, Geoff. 2016. “Haiti’s Army, Stabilization and Security Sector Governance”. Stability: International Journal of Security \& Development, 5(1): 14-35.

Cockayne, James. 2009. “Winning Haiti’s Protection Competition: Organized Crime and Peace Operations Past, Present and Future”. International Peacekeeping 16(1): 77-99. Cosgrove-Mather, Bootie. 2004. "Haiti's Aristide Warns Of Killings”. CBS News, February 24.

Cox, Robert W. 1981. "Social Forces, States and World Orders: Beyond International Relations Theory. Millenium: Journal of International Studies, Vol. 10, No. 2.

Cox, Robert W. 1983. "Gramsci, Hegemony and International Relations: An Essay in Method.” Millenium: Journal of International Studies, Vol. 12, No.2.

Democracy Now. 2004. "Head of U.S. Security Firm That Guarded Aristide Speaks Out”. Donais, Timothy. 2018. "Security sector reform and the challenge of vertical integration". Journal of Intervention and Statebuilding 12(1): 31-47.

Donais, Timothy. 2005. "Back to Square One: The Politics of Police Reform in Haiti." Civil Wars, Vol. 7, No. 3 (Autumn 2005).

Duffield, Mark. 2001. Global Governance and the New Wars: The Merging of Development and Security. Londres: Zed Books.

Dworken, Jonathan; Jonathan Moore and Adam Siegel. 1997. "Haiti Demobilization and Reintegration Program: An Evaluation Prepared for USAID”. The CNA Corporation. (IPR) 96-0104.

Engelberg, Stephen. 1994. "A haitian leader of paramilitaries was paid by CIA". The New York Times, October 08.

Gericke, Bradley. 2010. David Petraeus: A Biography. Santa Barbara: Greenwood.

Girard, Philippe. 2004. Clinton in Haiti: the 1994 U.S. Invasion of Haiti. New York: Palgrave Macmillan.

Gonzalez, David. 2000. "Final Haitian Vote Tally Shows Aristide Winning With 91.69\%”. The New York Times, November 30.

Goto, Stephen. 2016. “Ministerial Advisory Team - Haiti.” Upload em 2016. YouTube video, 21:07 min. https://www.youtube.com/watch?v=ZggPJotjPog.

Hallward, Peter. 2004. “Option zero in Haiti”. The New Left Review 27: 23-47. 
Jackson, Paul. 2011. “Security Sector Reform and State Building”. Third World Quarterly 32(10): 1803-1822.

Jackson, Paul. 2018. “Introduction: Second-Generation Security Sector Reform”. Journal of Intervention and Statebuilding 12(1): 1-10.

Jefferies, Judson. 2001. "The United States and Haiti: an exercise in intervention". Caribbean Quarterly 47(4): 71-94.

Keller, Dennis. 2010. “U.S. Military Forces and Police Assistance in Stability Operations: the Least-Worst Option to fill the U.S. Capacity Gap”. PKSOI Papers. Peacekeeping and Stability Operations Institute: U.S. Army War College.

Kolbe, Athena. 2013. “Revisiting Haiti’s Gangs and Organized Violence”. HASOW Discussion Paper 4.

Kovats-Bernat, Christopher. 2006. "Factional Terror, Paramilitarism and Civil War in Haiti: The View from Port-au-Prince, 1994-2004”. Anthropologica 48(1): 117-139.

Kreps, Sarah. 2007. “The 1994 Haiti intervention: A unilateral operation in multilateral clothes." Journal of Strategic Studies, 30:3, 449-474.

Malone, David. 1997. "Haiti and the international community: A case study”. Survival: Global Politics and Strategy 39(2): 126-146.

Mendelson-Forman, Johanna. 2006. Security Sector Reform in Haiti. International Peacekeeping, 13:1.

Mobekk, Eirin. 2001. "International Involvement in Restructuring and Creating Security Forces: The Case of Haiti”. Small Wars \& Insurgencies 12(3): 97-114.

Mobekk, Eirin. 2016. UN Peace Operations: Lessons from Haiti, 1994-2016. New York: Routledge.

Muggah, Robert. 2005. “Securing Haiti’s Transition: Reviewing Human Insecurity and the Prospects for Disarmament, Demobilization and Reintegration”. Genebra: Small Arms Survey.

Nairn, Allan. 1996. "Haiti Under the Gun: How U.S. Intelligence Has Been Exercising Crowd Control.” The Nation. 8-15 de Janeiro, 1996. https://libcom.org/library/ haiti-under-gun-allan-nairn.

Neild, Rachel. 1998. "Themes and Debates in Public Security Reform: a Manual for Civil Society: Police Training”. Washington Office on Latin America.

NSC. 1994?. National Security Council, NSC Records Management System, and NSC Inter-American Affairs Office, “Declassified Documents Concernining Haiti,” Clinton Digital Library, accessed February 4, 2021, https://clinton.presidentiallibraries.us/ items/show/101184.

OEA. 1991. Reunion ad hoc de ministros de relaciones exteriores, Acta de la primera sesion. OEA/Ser.F/V.1. MRE/ACTA 1/91. 2 octubre 1991. 
OEA. 1998. Comissão Interamericana de Direitos Humanos. OEA/Ser.L/V/II.98. doc. 6 rev. 13 April 1998.

OEA. 2000. Final Report: The Election Observation Mission for the Legislative, Municipal and Local elections in Haiti. February to July, 2000. OEA/Ser. G CP/doc.3383/00. ONU. 1993a. S/RES/841. New York, 16 jun.

ONU. 1993b. Report of the Secretary-General. A/47/1000. S/26297. New York, 13 ago.

ONU. 1993c. S/RES/861. New York, 27 ago.

ONU. 1993d. Letter dated 26 July 1993 from the Secretary-General addressed to the President of the Security Council. S/26180. New York, 28 jul.

ONU. 1993e. S/RES/867. New York, 23 set.

ONU. 1993f. S/RES/873. New York, 13 out.

ONU. 1993g. S/RES/875. New York, 16 out.

ONU. 1994. Report of the Secretary-General on the United Nations Mission in Haiti. S/1994/828. New York, 15 jul.

ONU. 1994a. S/RES/940. New York, 31 jul.

ONU. 1995. Report of the Secretary-General on the Question Concerning Haiti. S/1995/46. New York, 17 jan.

ONU. 2004. Report on the Secretary-General on Haiti. S/2004/300. New York, 16 abr. ONU. 2004a. S/RES/1529. New York, 29 fev.

ONU. 2008. United Nations Peacekeeping Operations: Principles and Guidelines. 2008. ONU. 2014. S/RES/2151. New York, 28 abr.

Pamphile, Leon. 2015. Contrary Destines: A Century of America's Occupation, Deoccupation, and Reoccupation of Haiti. Gainesville: University Press of Florida.

Paris, Roland. 2010. “Saving liberal peacebuilding”. Review of International Studies 36 337-365.

Raspberry, William. 1992. "Nightmare in Haiti”, The Washington Post, September 04.

Richmond, Oliver. 2012. "Para além da posse local na arquitetura do peacebuilding internacional”. In O Silêncio das Missões de Paz. São Paulo: EDUC (Org. Reginaldo Mattar Nasser), pp. 27-68.

Robinson, William I. 1996. Promoting polyarchy: Globalization, US intervention, and hegemony. Cambridge: Cambridge University Press.

Sedra, Mark. 2010. (ed.): The Future of Security Sector Reform. Waterloo: The Centre for International Governance Innovation.

Sedra, Mark. 2018. “Adapting security sector reform to ground-level realities: The transition to a second-generation model". Journal of Intervention and Statebuilding 12(1): 48-63. 
Smarth, Luc. 1998. Les organisations populaires en Haiti: Une étude exploratoire de la zone métropolitaine de Port-au-Prince. Port-au-Prince: Centre de recherches sociales et de diffusion populaire.

Sprague, Jeb. 2012. Paramilitarism and the Assault on Democracy in Haiti. New York: Monthly Review Press.

Trouillot, Michel-Rolph. 1990. Haiti: State Against Nation. The Origins \& Legacy of Duvalierism. New York: Monthly Review Press.

US. 1994. Presidential Decision Directive/NSC-25. The White House, Washington. May 3, 1994. Disponível em Federation of American Scientists, Intelligence Resource Program.

US. 1997. "Policing in Emergin Democracies: Workshop Papers and Highlights." National Institute of Justice, U.S. Department of Justice; Bureau of International Narcotics and Law Enforcement Affairs, U.S. Department of State. Washington, D.C., December 14-15, 1995.

US. 1999. "Foreign Assistance: Rule of Law Funding Worldwide for Fiscal Years 1993-98". Report to Congressional Requesters. United States General Accounting Office.

US. 2000. "Foreign Assistance: Lack of Haitian Commitment Limited Success of U.S. Aid to Justice System”. Testimony of Jess T. Ford Before the Committee on International Relations, House of Representatives. Unites States General Accounting Office.

US. 2005. "The United States and International Civilian Policing (CIVPOL)." Fact Sheet, Bureau for International Narcotics and Law Enforcement Affairs. Washington, D.C., May 18, 2005.

USAID. 2015. Haiti Rule of Law Assessment: Final Report. April 2015.

Weiner, Tim; Stephen Engelberg and Howard French. 1993. "CIA Formed Haitian Unit Later Tied to Narcotics Trade". The New York Times, November 14.

Wikileaks. 2008. "INL visitors get first-hand overview of NAS programs". Novembro, 28. 